\title{
AMENDMENTS
}

\section{Publisher Correction: Dimensionally and environmentally ultra-stable polymer composites reinforced with carbon fibres}

\author{
J. V. Anguita, C. T. G. Smith D, T. Stute, M. Funke, M. Delkowski and S. R. P. Silva (D)
}

Correction to: Nature Materials https://doi.org/10.1038/s41563-019-0565-3, published online 23 December 2019.

In the version of this Article originally published, Extended Data Figs. 2 and 3 were mistakenly swapped. This has now been corrected.

Published online: 11 February 2020

https://doi.org/10.1038/s41563-020-0617-8

(c) The Author(s), under exclusive licence to Springer Nature Limited 2020

\section{Publisher Correction: Dimensionally and environmentally ultra-stable polymer composites reinforced with carbon fibres}

\author{
J. V. Anguita D, C. T. G. Smith D, T. Stute, M. Funke, M. Delkowski and S. R. P. Silva (D)
}

Correction to: Nature Materials https://doi.org/10.1038/s41563-019-0565-3, published online 23 December 2019.

In the version of this Article originally published, J. V. Anguita's ORCID was missing; it should have been 0000-0002-7410-6620.

Published online: 13 January 2020

https://doi.org/10.1038/s41563-020-0609-8

(C) The Author(s), under exclusive licence to Springer Nature Limited 2020

\section{Publisher Correction: Electrical switching in a magnetically intercalated transition metal dichalcogenide}

Nityan L. Nair, Eran Maniv, Caolan John, Spencer Doyle, J. Orenstein and James G. Analytis (iD

Correction to: Nature Materials https://doi.org/10.1038/s41563-019-0518-x, published online 4 November 2019.

In the version of this Letter originally published, James G. Analytis was incorrectly indicated as an equally contributing author. Also, in the PDF version, the text 'However, only the antidamping term has $\mathbf{p}=\hat{\mathbf{z}} \times \mathbf{J}$ parallel to the applied current pulse $\mathbf{J}$ ' should have read 'However, only the antidamping term has $\mathbf{B}_{\text {eff }}^{\mathrm{AD}}$ parallel to the applied current pulse $\mathbf{J}$ '; this text was correct in the original HTML version. These issues have now been corrected.

Published online: 13 November 2019

https://doi.org/10.1038/s41563-019-0553-7

(c) The Author(s), under exclusive licence to Springer Nature Limited 2019 